\title{
PENGARUH LITERASI KEUANGAN TERHADAP INTENSI BERINVESTASI DENGAN MODERASI SELF REGULATORY FOCUS.
}

\author{
Hakim Manurung, Resi Bramani Y, Immanuel Ricky, Darmanto \\ e-mail: hmanurung@gmail.com
}

\section{Program MM Sekolah Bisnis dan Ekonomi Universitas Prasetiya Mulya}

\begin{abstract}
Financial literacy is the understanding, planning and regulation of financial conditions by considering the risks prior to make a decision to invest both in short and long term for the welfare of the individual. Financial literacy has an important role particularly in the decisionmaking process to invest in financial products. This study examines the extent to which the influence of financial literacy on investment intentions with the Self Regulatory Focus moderation. The results of this study described that when the individual has a higher financial literacy, he or she will tend to have a high intention to invest. Likewise with the moderation of Self Regulatory focus on groups of prevention who have high financial literacy will tend to have a high intention to invest.
\end{abstract}

\section{Kata kunci:}

Financial Literacy, self regulatory focus, prevention, promotion, intention, investment

\section{Sari Pati}

Literasi keuangan merupakan pemahaman, perencanaan dan pengaturan kondisi keuangan dengan mempertimbangkan resiko sebelum mengambil keputusan untuk berivestasi baik jangka pendek maupun jangka panjang demi kesejahteraan individu tersebut. Literasi keuangan berperan penting dalam proses pengambilan keputusan untuk melakukan investasi produk keuangan. Penelitian ini menguji sejauh mana pengaruh literasi keuangan terhadap intensi berinvestasi dengan adanya moderasi Self Regulatory Focus. Hasil dari penelitian ini memaparkan bahwa semakin tinggi literasi keuangan yang dimiliki seseorang maka dia akan cenderung memiliki intensi yang tinggi untuk berinvestasi. Demikian juga dengan adanya moderasi Self Regulatory focus pada kelompok prevention yang memiliki literasi keuangan yang tinggi maka akan cenderung memiliki intensi yang tinggi untuk berivestasi.

\section{PENDAHULUAN}

Perkembangan teknologi dan ilmu pengetahuan sangat berkontribusi kepada industri perbankan khususnya produk-produk investasi di Indonesia saat ini. Banyak layanan produk keuangan ditawarkan melalui online yang memudahkan calon konsumen untuk memilah produk keuangan yang sesuai dengan kebutuhan dan keinginannya. Demikian juga dunia investasi seperti pasar modal fundamental tidak terlepas dari kemajuan teknologi dan ilmu pengetahuan saat ini. Pasar modal seperti menjadi trend bagi mereka yang bekerja namun ingin mendapatkan tambahan penghasilan dengan tidak harus membutuhkan presensi mereka secara fisik dalam bisnis sampingan tersebut. Tentunya sebelum melakukan aktivitas dalam pasar modal baik yang spekulatif maupun fundamental memerlukan pengetahuan setidaknya 
yang sangat mendasar tentang produk keuangan tersebut. Sehingga para pemain di pasar modal tersebut sejatinya sudah dibekali ilmu keuangan atau disebut dalam kelompok literasi keuangan yang memadai.

Namun tidak jarang juga kita jumpai individu yang nekad untuk melakukan aktivitas di pasar modal atau investasi lainnya tanpa pengetahuan yang cukup, sehingga banyak mengalami kegagalan dan tertipu dengan produk investasi bodong. Apakah memang benar adanya hubungan antara literasi keuangan dengan intensi berinvestasi, atau memang intensi berinvestasi yang diperlukan hanya modal nekad tanpa perlu literasi keuangan yang memadai. Untuk pendalaman lebih lanjut, penelitian ini akan mendiskusikannya, namun tidak hanya hubungan antara literasi keuangan dengan intensi berinvestasi namun dengan adanya self regulatory focus akankah memoderasi hubungan antara literasi keuangan dengan intensi berivestasi.

\section{Tujuan Penelitian}

Penelitian ini bertujuan untuk mendapatkan pemaparan yang dapat menjawab hal-hal berikut:

1. Pengaruh Literasi Keuangan terhadap Intensi berivestasi.

2. Dengan adanya moderasi Self Regulatory Focus akan memperkuat atau memperlemah hubungan antara Literasi Keuangan dengan Intensi berinvestasi.

\section{Literasi Keuangan}

Kebutuhan tentang literasi keuangan belakangan ini semakin mendesak dengan adanya berbagai upaya yang dilakukan individu atau sekelompok orang untuk menawarkan investasi baik dalam sektor riil maupun non riil. Namun tidak sedikit dari investasi yang ditawarkan tersebut ternyata bodong atau berkedok penipuan. Menurut beberapa pengamat investasi, ada keyakinan bahwa banyaknya korban penipuan dalam kasus investasi bodong diakibatkan lemahnya literasi keuangan yang dimiliki korban. Otoritas Jasa Keuangan - OJK dalam penilitiannya tahun 2016 mengungkapkan masyarakat Indonesia memiliki literasi keuangan yang masih rendah dimana hanya sekitar $29 \%$ masyarakat Indonesia yang sudah melek keuangan, untungnya persentasi ini meningkat dari tahun ke tahun.

Literasi keuangan merupakan kemampuan untuk menimbang dan mengambil keputusan yang efektif sehubungan dengan penggunaan dan pengelolaan uang. (Noctor et al., 1992). Sementara literasi keuangan personal adalah kemampuan untuk membaca, menganalisa, mengatur dan mengkomunikasikan tentang keadaan keuangan personal yang mempengaruhi kesejahteraannya secara materi, dalam hal ini termasuk cara melihat pilihan keuangan, mendiskusikan masalah keuangan tanpa ada ketidaknyamanan, rencana masa depan yang mempengaruhi keputusan keuangan setiap harinya, meliputi kegiatan dalam ekonomi secara umum (Vitt et al., 2000). Sementara menurut Kim (2001) literasi keuangan adalah kemampuan dasar yang dibutuhkan masyarakat agar dapat bertahan hidup dalam kehidupan modern. Literasi keuangan merupakan kemampuan personal untuk memahami dan membuat konsep keuangan yang berguna dalam hidupnya (Servon and Kaestner 2008). 
Dalam beberapa tahun terakhir, literasi keuangan lebih terfokus pada produk perbankan terbaru atau terpopuler seperti pasar modal dan investasi jangka panjang. Penelitian Bank of Japan, 2016 tentang literasi keuangan pada masyarakat Jepang, menitikberatkan pada pengetahuan dasar keuangan, perencanaan keuangan serta kemampuan untuk menghindari resiko yang akan terjadi dari investasi yang dilakukan.

Menurut lembaga Otoritas Jasa Keuangan (OJK) dalam survei yang dilakukan pada tahun 2013, menyatakan bahwa secara defenisi literasi diartikan sebagai kemampuan dalam memahami dan mengelola dana yang dimiliki agar berkembang dan hidup bisa lebih sejahtera dimasa yang akan datang, Penelitian ini mengukur beberapa variabel yang mempengaruhi literasi keuangan yang terdiri dari tiga kelompok variabel yaitu pengetahuan, perencanaan dan penghindaran resiko dimana pengukuran masing-masing variabel tersebut digabung dalam kuesioner yang diuji pada responden. Hasil dari data responden tersebut dikategorikan menjadi dua yaitu tinggi dan rendahnya literasi keuangan. Dari berbagai pemaparan yang telah dilakukan para peneliti sebelumnya, dan menggabungankannya dengan pemikiran penulis sehingga hipotesa dapat dibangun sebagai berikut :

H1. Literasi keuangan yang tinggi akan meningkatkan intensi berinvestasi.

\section{Self Regulatory Focus}

Pendekatan Self Regulatory Focus merupakan skenario yang digunakan oleh individu untuk mengatur atau meregulasi perilakunya dalam mencapai tujuan (Tumasjan dan Braun 2012). Pendekatan SRF ini pertama kali dikembangkan oleh Higgins (1998) yang mana regulatory focus digambarkan sebagai perbedaan yang besar dalam proses yang melalui apakah seseorang cenderung memilih kesenangan atau menghindari rasa sakit atau kerugian. Regulatory focus theory (Higgins 1997, 1998) membandingkan antara dua prinsip-prinsip motivasi yaitu promotion dan prevention focus.

Pendekatan Self Regulatory Focus dengan mengelompokkannya menjadi dua bagian berdasarkan perbedaan kebutuhan antara lain prevention dan promotion (Higgins 1997, 1998). Kelompok promotion lebih berorientasi pada keuntungan, kemajuan dan pencapaian dan mempunyai komitmen yang tinggi. Pada dasarnya mereka yang dikelompokkan dalam promotion ini karena kesamaan dalam hal pencapaian tujuan, harapan dan keinginan. Dilain pihak kelompok prevention adalah mereka yang berorientasi pada pengambilan resiko namun berusaha mencari cara untuk menghindari keggagalan dan kesalahan. Dan kelompok prevention pada dasarnya dikelompokkan berdasarkan kewajiban, tanggung jawab dan keselamatan. Sehingga jika dikaitkan dengan investasi produk keuangan, maka mereka yang berada di kelompok prevention dapat dikategorikan sebagai pengambil resiko dalam investasi namun tetap mengetahui bagaimana untuk berhasil atau menghindari kegagalan.

Secara spesifik Higgins (1997) menyatakan bahwa seorang memiliki dua sistem self regulation dasar. Pertama meregulasi pencapaian dari penghargaan dan memfokuskan pada tujuan promotion. Kedua meregulasi pencegahan hukuman atau konsekuensi negatif dan memfokuskan seseorang pada tujuan prevention. Promotion goals menggambarkan "ideal self" dan termasuk harapan, keinginan dan aspirasi, sedangkan prevention goals menggambarkan 
"ougth self" dan termasuk tanggung jawab dan kewajiban. Masing-masing regulatory focus memiliki konsekuensi yang berbeda untuk persepsi, pengambilan keputusan, emosi seperti perilaku dan kinerja individu (Higgins 1997). Berdasarkan pendekatan tersebut diatas dan digabungkan dengan pemikiran penulis sehingga dapat membangun hipotesis sebagai berikut:

H2. Self Regulatory Focus (Prevention dan Promotion) akan memperkuat hubungan antara

Literasi keuangan dan intensi berinvestasi.

\section{Intensi Berinvestasi}

Intensi merupakan persepsi pribadi terhadap kemungkinan untuk mengambil sikap (Fishbein and Ajzen 1975 in Sondari and Sudarsono 2015). Intensi juga dapat didefenisikan sebagai keinginan untuk melakukan suatu sikap dalam rentan waktu tertentu baik jangka pendek maupun jangan panjang (Roger \& Browly 1991). Sementara intensi pembelian adalah penentu utama suatu sikap sebelum mengambil keputusan untuk melakukan transaksi (Wiener \& Descher 2008).

Ada tiga hal yang terkandung dalam intensi yaitu sikap terhadap perilaku, norma subjektif dan norma kendali terhadap perilaku. Sikap terhadap perilaku ditentukan oleh analisa dan keyakinan akan menghasilkan sesuatu dari perilaku tersebut. Norma subjektif adalah hasil dari keyakinan seseorang akan pendapat orang lain mengenai suatu perilaku dan dia berusaha untuk menyelaraskan pandangannya terhadap perilaku tersebut. Sementara persepsi kendali adalah keyakinan seseorang bahwa dia yakin dapat melakukan perilaku tersebut. Perilaku sebagai variabel yang diukur dalam penelitan ini adalah intensi berinvestasi jangka panjang khususnya dibidang saham fundamental. Metode pengukuran intensi berinvestasi ini mengacu pada teknik proyeksi dimana teknik ini bersifat tidak terstruktur, berbentuk pertanyaan tidak langsung yang mendorong responden memproyeksikan motivasi, kepercayaan, sikap atau perasaan dasar mereka mengenai masalah yang diteliti (Malhotra 2004). Dalam teknik proyeksi, responden diminta untuk memproyeksikan perilaku orang lain, tidak diminta menjelaskan perilaku mereka sendiri. Dalam menginterpretasikan perilaku orang lain, responden secara tidak langsung memproyeksikan motivasi, kepercayaan, sikap atau perasaan mereka sendiri terhadap sebuah situasi. Namun untuk menghindari jawaban normatif sengaja dimasukkan pertanyaan yang didesain sedemikian rupa dengan mencantumkan pertanyaan skrip dan fundamental tentang intensi berivestasi jangka panjang berupa saham fundamental.

\section{Gap Penelitian}

Para peneliti terdahulu telah banyak yang sudah melakukan penelitian baik deskriptif maupun kausalitas tentang literasi keuangan dan intensi berinvestasi. Namun penelitan yang secara spesifik memadukan moderasi Self Regulatory Focus dalam pengukuran korelasi literasi keuangan dengan intensi berinvestasi, sepanjang pengetahuan penulis belum dilakukan. Untuk itu dengan penelitian ini kami mencoba melakukan pendekatan dengan memadukan moderasi Self Regulatory Focus (Higgins 1997, 1998) dalam pengukuran hubungan antara literasi keuangan (OECD 2016) dan intensi berinvestasi (Kusuma 2005).

\section{METODOLOGI PENELITIAN}


Penelitan ini bersifat kausalitas (hubungan sebab akibat) yang mana bertujuan untuk mengetahui hubungan antara independent variables dan dependent variables. Dalam penelitian ini juga bertujuan untuk mengetahui kekuatan hubungan antara variabel tersebut yang dimoderasi oleh independent variable, self regulatory focus (Higgins 2009).

Alat ukur (kuesioner) yang digunakan dalam penelitian ini mengacu pada pendekatan yang dilakukan OECD dan Survei Bank of Japan, 2016 tentang pengukuran tingkat literasi keuangan dari responden di Jepang. Di dalam survei tersebut ada beberapa hal utama yang menjadi titik berat penelitian yaitu pengetahuan dasar tentang keuangan, perencanaan dan penghindaran resiko investasi. Dari setiap pertanyaan yang diajukan diperiksa jawaban kemudian dilakukan pembobotan nilai sehingga bisa mengkategorikan tingkat literasi keuangan responden tinggi atau rendah.

Kemudian untuk pengukuran Self Regulatory Focus menggunakan pendekatan Fellner et al 2007, dalam penelitian "Regulatory Focus Scale (RFS): Development of a Scale to Record Dispositional Regulatory Focus".

Sementara untuk mengukur intensitas berinvestasi mengacu pada pendekatan yang dilakukan dalam penelitian (Kusuma 2005). Penelitian kali ini lebih memfokuskan pada intensi berinvestasi di pasar modal fundamental dan pertanyaannya didesain sedemikian rupa sesuai dengan tujuan penelitian dengan menggunakan teknik proyeksi (Maholtra 2004).

Metode pengumpulan data dalam penelitian ini dilakukan dengan cara menyebar kuesioner melalui media online seperti email dan whatsapp group yang mana kuesioner sudah dikemas dengan format yang ada dalam Google doc sehingga memudahakn responden untuk meresponse kuesioner melalui media online juga. Metode pemilihan responden yaitu purposive and judgment sampling dimana responden yang diberikan kuesioner dianggap cocok sebagai responden dalam penelitan ini. Namun responden tersebut telah memenuhi kriteria dari penghasilan dan pengetahuan. Populasi responden tidak terbatas (non restricted sampling) selama mereka terhubung dengan media online seperti email dan whatsapp untuk mengisi kuesioner yang mereka terima. Data primer yang didapatkan langsung dari sumbernya telah disusun dalam bentuk sheet dan bentuk grafik dari google form sehingga memudahkan penulis untuk menginput data untuk dianalisa selanjutnya.

\section{ANALISIS DATA}

Untuk menganalisa data, diperlukan bantuan perangkat lunak SPSS 17.0. Pertama-tama dilakukan pre-test untuk uji reliabilitas dan validitas pertanyaan yang diajukan ke responden dengan cara factor analysis pada 32 data responden. Data yang didapatkan melalui google form, dilakukan beberapa tahapan agar data tersebut dapat diukur dengan cara membuat dummy untuk setiap data yang non scale diubah menjadi data dengan skala Lickert. Kemudian data tersebut dianalisa dengan factor analysis untuk memeriksa KMO dan anti image harus minimal 0.5, Awalnya ada beberapa ditemukan anti image serta KMO yang dibawah 0,5 kemudian dilakukan penyederhanaan beberapa pertanyaan dengan cara mengelimir sebagian pertanyaan yang tidak relevan, setelah itu dilakukan factor analysis kembali sehingga 
didapatkan semua anti image dan KMO sudah diatas 0.5. Selanjutnya kuesioner tersebut disebar sama halnya dengan prosedur awal melalui media online seperti email dan whatsapp group. Target data responden yang diharapkan minimal 120 data responden untuk kebutuhan 4 kelompok dimana masing-masing tiap kelompok diisi oleh 30 data responden. Namun penulis tidak membatasi jumlah data responden yang masuk melainkan hanya ada batasan waktu yaitu maksimal 1 minggu. Dengan asumsi untuk mendapatkan 120 responden yang tepat sesuai dengan kriteria kelompok maka dibutuhkan data lebih dari 120 untuk mengantisipasi error atau ketidak sesuaian dengan yang diharapkan. Setelah memenuhi kriteria waktu yang telah ditentukan, data responden yang didapatkan mencapai 158 dengan response rate yang cukup baik. Data tersebut kemudian diperiksa apakah ada missing variable, dan ternyata data yang masuk semuanya valid. Data 160 responden tersebut dipilih kembali agar memenuhi jumlah kelompok high, low dan prevention, promotion masing-masing dengan jumlah yang sama atau tidak mempunyai perbedaan jumlah yang signifikan.

Dari data responden yang telah tersusun dalam google form, kemudian dilakukan pengkodean dan dummy pada data yang non scale untuk dijadikan data yang mengacu pada skala Likert agar dapat diukur menggunakan perangkat lunak SPSS 17.0. Setelah mendapatkan semua data dalam bentuk skala, kemudian dicari rata-rata dari masing-masing baik literasi keuangan maupun self-regulatory focus. Kemudian data dianalisa menggunakan frequency untuk menentukan median split. Dimana setiap responden yang mempunyai rata-rata dibawah median tersebut dikategorikan low literacy dan SRF - promotion dengan coding 1 demikian juga sebaliknya yang mempunyai rata-rata diatas median dikategorikan high literacy dan SRF Prevention dengan coding 2 . Semetara pernyataan yang mengukur Intensi berivestasi hanya dihitung rata-ratanya saja. Dari tiga data variabel tersebut dianalisa menggunakan general linear model (GLM) univariate. Analisa GLM Univariate ini bertujuan untuk mengetahui hubungan antara 2 atau lebih independent variable dengan satu dependent variable. Dalam independent variable tersebut ada masing-masing 2 kelompok yaitu low literacy dan high literacy serta kelompok promotion dan prevention. Dari hasil analisa GLM Univariate tersebut dapat ditemukan koefisien dari persamaan regresi lineranya. Selanjutnya untuk mengetahui hubungan masing-masing kelompok ini dengan dependent variable dilakukan pengelompokan atau kategorik menggunakan metode Rerata sel (Agung 2003).

\section{HASIL PENELITIAN}

Jumlah data responden yang didapatkan sebanyak 158. Semua data yang masuk layak untuk dianalisa karena seluruh pertanyaan dijawab lengkap oleh masing-masing responden. Analisa GLM univariate dari data responden tersebut menunjukkan adanya korelasi antara literasi keuangan dengan intensi berinvestasi. Dalam hal ini Hipotesa I yang diajukan terbukti signifikan (Sig<0.05) seperti ditunjukkan pada tabel berikut: 
Tabel 1.0 Parameter Estimates

\begin{tabular}{|c|c|c|c|c|c|c|c|c|c|}
\hline \multirow[t]{2}{*}{ Parameter } & \multirow[t]{2}{*}{ B } & \multirow{2}{*}{$\begin{array}{l}\text { Std } \\
\text { Error }\end{array}$} & \multirow[t]{2}{*}{$\mathbf{t}$} & \multirow[t]{2}{*}{ Sig } & \multicolumn{2}{|c|}{$\begin{array}{c}\text { Confidence } \\
\text { interval (95\%) }\end{array}$} & \multirow{2}{*}{$\begin{array}{l}\text { Partial } \\
\text { Eta } \\
\text { Square } \\
\text { d }\end{array}$} & \multirow{2}{*}{$\begin{array}{l}\text { Noncent } \\
\text { parameter }\end{array}$} & \multirow{2}{*}{$\begin{array}{l}\text { Observe } \\
\text { d power }\end{array}$} \\
\hline & & & & & $\begin{array}{l}\text { Lower } \\
\text { boun } \\
\text { d }\end{array}$ & $\begin{array}{l}\text { Upper } \\
\text { boun } \\
\text { d }\end{array}$ & & & \\
\hline Intercept & $\begin{array}{c}3.78 \\
8\end{array}$ & .068 & $\begin{array}{c}55.3 \\
57\end{array}$ & $\begin{array}{c}.00 \\
0\end{array}$ & 3.653 & 3.923 & .952 & 55.357 & 1.000 \\
\hline [Literasi=1.00] & $\begin{array}{c}- \\
.228\end{array}$ & .110 & $\begin{array}{c}- \\
2.06 \\
9\end{array}$ & $\begin{array}{c}.04 \\
0\end{array}$ & -.445 & -.010 & .027 & 2.069 & .538 \\
\hline [Literasi=2.00] & $0^{b}$ & . & . & . & . & . & . & . & . \\
\hline $\begin{array}{l}\text { [Literasi=1.00] } \\
*[\mathrm{SRF}=1.00]\end{array}$ & $\begin{array}{c}- \\
.263\end{array}$ & .112 & $\begin{array}{c}- \\
2.34 \\
5\end{array}$ & $\begin{array}{c}.02 \\
0\end{array}$ & -.484 & -.041 & .034 & 2.345 & .644 \\
\hline $\begin{array}{l}{[\text { Literasi }=1.00]} \\
*[\mathrm{SRF}=2.00] \\
\end{array}$ & $0^{b}$ & $\cdot$ & . & . & $\cdot$ & $\cdot$ & $\cdot$ & $\cdot$ & . \\
\hline $\begin{array}{l}\text { [Literasi=2.00] } \\
*[\mathrm{SRF}=1.00]\end{array}$ & $\begin{array}{c}- \\
.233\end{array}$ & .100 & $\begin{array}{c}- \\
2.33 \\
9\end{array}$ & $\begin{array}{c}.02 \\
1\end{array}$ & -.430 & -.036 & .034 & 2.339 & .642 \\
\hline $\begin{array}{l}\text { [Literasi }=2.00] \\
*[\mathrm{SRF}=2.00]\end{array}$ & $0^{b}$ & . &. & . & . & . & . & . & . \\
\hline
\end{tabular}

a. Computed using alpha $=.05$

b. This parameter is set to zero because it is redundant.

\section{Sumber : Hasil olahan datas SPSS 17.0}

Tabel 2.0 : Nilai $\beta$ sebagai intersep dan koefisien regresi linear.

\begin{tabular}{|l|c|c|}
\hline \multicolumn{1}{|c|}{ Parameter } & $\mathrm{B}$ & $\mathrm{B}$ \\
\hline Intercept & $\beta 0$ & 3.788 \\
{$[$ Literasi $=1.00]$} & $\beta 1$ & -.228 \\
{$[$ Literasi $=2.00]$} & & $0^{\mathrm{b}}$ \\
{$[$ Literasi $=1.00] *[\mathrm{SRF}=1.00]$} & $\beta 2$ & -.263 \\
{$[$ Literasi $=1.00] *[\mathrm{SRF}=2.00]$} & & $0^{\mathrm{b}}$ \\
{$[$ Literasi $=2.00] *[\mathrm{SRF}=1.00]$} & $\beta 3$ & -.233 \\
{$[$ Literasi $=2.00] *[\mathrm{SRF}=2.00]$} & & $0^{\mathrm{b}}$ \\
\hline
\end{tabular}

Sumber : Hasil olahan data SPSS 17. 
Dari hasil olahan data diatas, dapat dilihat niai $\beta 0, \beta 1, \beta 2$ dan $\beta 3$. Nilai $\beta$ tersebut akan dimasukkan dalam persamaan regresi linear sebagai berikut :

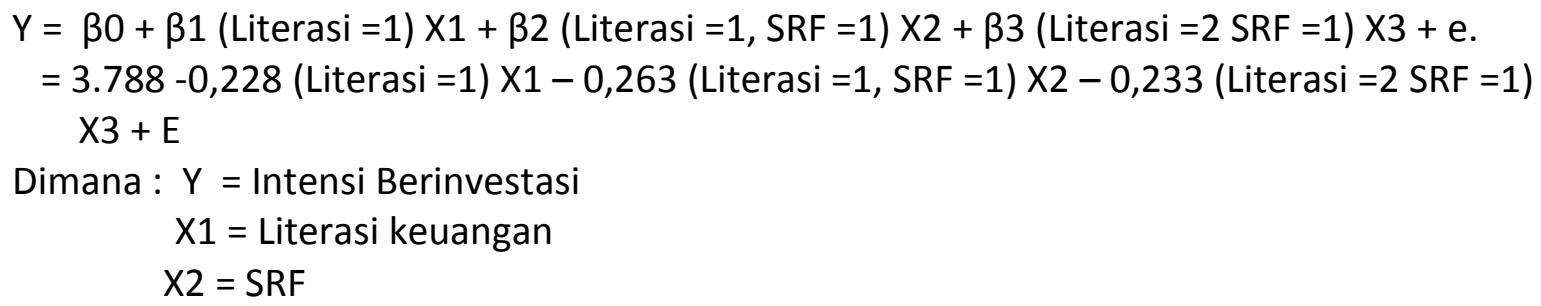

Pendekatan lain untuk menentukan persamaan regresi juga dapat dilakukan dengan persamaan linear berikut, namun yang membedakan adalah pengukuran literasi keuangan sesuai dengan skala metrik bukan kategorik ( $h i g h$ dan low) yaitu :

$Y=60+61 X 1+62 \times 2+63 \times 1 \times 2+64 X 4+6 n X n$

Dimana $: Y=$ Intensi Berinvestasi

$\mathrm{X} 1$ = Literasi Keuangan

$\mathrm{X} 2$ = SRF (dummy 1, prevention; 0 , promotion)

Jika B1 = positif, maka literasi keuangan tinggi akan mempengaruhi intensi berinvestasi yang tinggi pula, demikian sebaliknya.

Jika B2 = positif maka dapat disimpulkan bahwa SRF prevention akan memperkuat hubungan literasi keuangan yang tinggi dengan intensi berivestasi dan demikian sebaliknya.

Jika B3 = positif maka dapat disimpulkan bahwa SRF promotion akan memperkuat hubungan antara literasi keuangan yang tinggi dengan intensi berivestasi dan demikian sebaliknya.

Namun pendekatan pertama diatas yang menjadi dasar bagi peneliti untuk melihat hubungan antara kelompok independent variables terhadap dependent variabel. Untuk melihat hubungan dari variabel-variabel tersebut data parameter estimate atau koefisien $\beta$ ditransformasikan ke dalam tabel rerata sel seperti berikut:

Tabel 3.0 : Rerata Sel (Pengelompokan)

\begin{tabular}{|c|c|c|c|c|}
\hline & \multicolumn{2}{|c|}{ Self Regulatory Focus - SRF } & \multirow[t]{2}{*}{ Selisih } \\
\hline & & Prevention $=2$ & Promotion $=1$ & \\
\hline \multirow{3}{*}{$\begin{array}{l}\text { Literasi } \\
\text { Keuangan }\end{array}$} & Tinggi $=2$ & $\beta 0$ & $\beta 0-\beta 3$ & $\beta 3$ \\
\hline & Rendah = 1 & $\beta 0-\beta 1$ & $\beta 0-\beta 1-\beta 2$ & $\beta 2$ \\
\hline & Selisih & $\beta 1$ & $\beta 1+\beta 2-\beta 3$ & \\
\hline
\end{tabular}

Dari hasil pengelopokan tersebut diatas maka hasil penelitian ini dapat diinterpretasikan sebagai berikut:

Nilai $\beta 1=-0,228$ dengan nilai sig $=0,04(<0,05)$ memenuhi kriteria signifikansi data, dengan demikian dapat disimpulkan khusus untuk kelompok SRF Prevention, responden yang memiliki literasi tinggi memiliki intensi berivestasi yang tinggi dibandingkan dengan yang literasi rendah. 
Kemudian $\beta 2=-0,263$ dengan nilai sig $=0,02(<0,05)$ memenuhi kriteria signifikasi data, oleh karena itu dapat disimpulkan bahwa khusus untuk responden dengan literasi keuangan yang rendah, dan dengan SRF prevention memiliki Intensi berinvestasi lebih besar dibanding responden yang SRF promotion.

Kemudian $\beta 3=-0,233$ dengan nilai sig $=0,021(<0,05)$ memenuhi kriteria signifikasi, oleh karena itu dapat disimpulkan bahwa khusus kelompok reponden yang memiliki literasi keuangan yang tinggi, dan SRF prevention cenderung mempunyai intensi berinvestasi lebih besar dibandingkan dengan yang SRF Promotion.

\section{KESIMPULAN}

Berdasarkan hasil penelitian dapat disimpulkan bahwa literasi keuangan mempengaruhi intensi berivestasi di pasar modal fundamental. Hasil penelitian ini mengungkapkan bahwa ada kecenderungan jika semakin tinggi literasi keuangan seseorang maka semakin tinggi intensinya untuk berinvestasi di pasar modal fundamental. Demikian sebaliknya semakin rendah literasi keuangan seseorang maka kecenderungan intensinya berinvestasi di pasar modal fundamental akan semakin rendah.

Kemudian, dengan adanya self regulatory focus khususnya kelompok Prevention cenderung mempunyai intensi berivestasi yang tinggi jika dibekali dengan literasi keuangan yang tinggi . Argumentasi yang lainnnya, walapun seseorang mempunyai literasi keuangan yang rendah namun berada dalam kelompok SRF Prevention ada kecenderungan memiliki intensi yang tinggi untuk berinvestasi. Sehingga dapat disimpulkan moderasi SRF prevention sangat kuat memoderasi hubungan antara literasi keuangan dengan intensi berinvestasi. Namun demikian sebaliknya pada SRF promotion dimana, walaupun seseorang memiliki literasi keuangan yang tinggi dan berada di dalam kelompok SRF promotion maka ada kecenderungan intensi seseorang tersebut semakin rendah untuk berivestasi. Dari hasil argumentasi tersebut diatas, maka dapat disimpulkan bahwa penelitian ini mengkonfirmasi hipotesis I dan II yang dibangun dan terbukti signifikan.

\section{Implikasi Managerial}

Dengan mempertimbangan hasil penelitian ini, penulis mengusulkan agar perusahaan jasa investasi jangka panjang khususnya pasar modal fundamental, perlu memperhatikan literasi keuangan calon investornya sebagai bagian dari strategi pemasaran agar tepat sasaran.. Ada beberapa langkah yang bisa dilakukan antara lain dengan menyelenggarakan pelatihan gratis tentang keuangan yang meliputi dasar-dasar keuangan, pengetahuan perencanaan dan resiko investasi melalui kerjasama dengan instansi perkantoran atau lembaga pendidikan.

Teknik moderasi Prevention dan Promotion, terbukti dapat memperkuat dan memperlemah korelasi antara literasi keuangan dan intensi berivestasi sehingga moderasi yang tepat dapat digunakan dalam strategi pemasaraan dalam hal ini moderasi prevention terbukti signifikan dapat memperkuat hubungan antara literasi keuangan dan intensi berinvestasi. Dengan demikian jika dipadukan literasi keuangan dan moderasi motivasi prevention dalam strategi pemasarannya akan menghasilkan dampak yang signifikan. 


\section{Limitasi dan saran}

Penulis menyadari penelitian ini mempunyai keterbatasan baik dari jumlah responden dan metode pengumpulan data. Sebaiknya untuk penelitian ini jumlah responden 500 atau lebih namun komposisi data yang dapat dibagi menjadi 4 kelompok dengan perbedaan yang tidak terlalu signifikan. Kemudian metode pengumpulan data responden sebaiknya dengan tatap muka atau wawancara sehingga dapat benar-benar dikelompokkan bahwa responden tersebut masuk kategori tinggi atau rendah dalam literasi keuangan serta kelompok prevention atau promotion. Semakin banyak data yang valid dan reliable dapat meyakinkan peneliti bahwa data tersebut benar-benar mewakili data responden sesuai dengan harapan penulis. Untuk peneliti selanjutnya dapat meneliti yang menitik beratkan pada variasi independent variable atau dependent variable seperti intensi berinvestasi spekulatif (trading) atau model investasi syariah.

\section{REFERENSI :}

Agung, IGN. (2006), Penerapan Model Rerata-Sel Multivariat dan Model Ekonometri dengan SPSS, Yayasan SAD Bhakti, Jakarta.

Survei nasional literasi dan inklusi keuangan 2016, http://www.ojk.go.id (29 Agustus 2017).

Central Council for Financial Services Information, Secretariat: Public Relations Department, Bank of Japan, 2016.

Higgins ET. (1998), "Promotion and prevention: Regulatory focus as a motivational

principle", Advances in Experimental Social Psychology 30, M. P. Zanna (ed.).

Kim, Jinhee. (2001), "Financial Knowledge and Subjective and Objective Financial Wellbeing", Consumer Interests Annual, 47: 1-3.

ACCl Website, http://www.consumerinterests.org/files, (28 Aug 2017).

Kusuma (2005), "Pengaruh Karakteristik Konsumen Serta Stimulus Pemasaran Terhadap Intensi Untuk Membeli Produk Jangka Panjang", Universitas Indonesia, Jakarta.

Malhotra, N.K. (2004), "Marketing Research: An Applied Orientation" 4th Edition. New Jersey: Pearson Education Inc.

Noctor M, Stoney S, and Stradling R. (1992), "Financial Literacy: A Discussion of Concepts and Competences of Financial Literacy and Opportunities for its Introduction into Young People's Learning", National Foundation for Educational Research, London.

Servon, Lisa J and Kaestner R (2008), "Consumer Financial Literacy and the Impact of Online Banking on the Financial Behavior of Lower-Income Bank Customers", Journal of Consumer Affairs, 42 (Summer): 271-305.

Sondari MC. and Sudarsono R. (2015), "Using Theory of Planned Behavior in Predicting Intention to Invest: Case of Indonesia". International Academic Research Journal of Business and Technology, 1(2), 137-141.

Tumasjan A and Braun R (2012), "In the Eye of the Beholder: How Regulatory Focus and Self-efficacy Interact in Influencing Opportunity Recognition", Journal of Business Venturing 27(6): 622-636.

Vitt et al (2000), "Personal finance and the rush to competence: Financial literacy education in the U.S", Institute for Socio-Financial Studies, Middleburg VA. 